Mitsuru Higuchi Yanaze; Felipe Chibás Ortiz; Kleber Markus (Org.)

\section{MARKETING E COMUNICAÇÃOO DE PROJETOS SOCIOCULTURAIS:}

Experiências brasileiras e cubanas
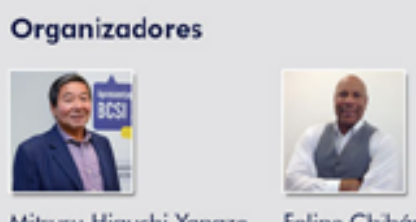

Felipe Chibás Ortiz

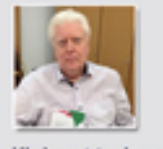

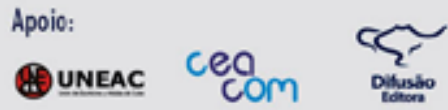

Marketing e comunicação de projetos socioculturais: experiências brasileiras e cubana

São Caetano do Sul, SP

Editora Difusão, 2015

407 páginas

Maurício Mário Monteiro

- Pós-doutor pela Universidade Estadual Paulista Júlio de Mesquita Filho (Unesp)

- Doutor e mestre em História Social pela Faculdade de Filosofia, Letras e Ciências Humanas da Universidade de São Paulo (FFLCH-USP)

- Professor do Programa de Pós-Graduação em Comunicação e dos cursos de Cinema e Rádio e TV da Universidade Anhembi Morumbi

- E-mail: mauriciomonteiro@hotmail.com 


\title{
Experiências além das fronteiras culturais
}

\author{
Experiences beyond the cultural frontiers
}

\section{Experiencias más allá de las fronteras culturales}

A inda que haja uma célebre obra que fale acerca das veias abertas de nossa latina América, bem sabemos quão fechadas são as fronteiras em termos de conhecimento entre os diversos países, que, por terem uma base de formação cultural em tantos pontos comum, se imaginaria serem próximos. Não são.

A ideia que temos sobre nossos vizinhos mais cercanosou mais lejanosé muito mais voltada a mitificações que a representações do que seria o real. E isso ocorre por diversos aspectos e, no caso brasileiro, o idioma é também um complicador, além de nossa presença quase continental sobre os demais, geograficamente menores. 0 intercâmbio, por outro lado, é o melhor caminho para fazer com que as fronteiras culturais sejam espaços de multiplicação de saberes, de troca proveitosa de experiências.

A obra Marketing e comunicação de projetos socioculturais: experiências brasileiras e cubanas mostra exatamente isso: encontro entre experiências que, se não houvesse empenho, não conversariam. 0 trabalho resulta do empenho e da parceria entre três pesquisadores - Mitsuru Higuchi Yanaze, Felipe Chibás Ortiz, Kleber Markus - que se enxergam além do alcance, entendendo que a troca entre dois países vastamente ricos e com histórias tão diferentes pode resultar em ampliação de fronteiras do pensamento.

O livro se compõe de três partes: uma para dar conta das aproximações conceituais, pesquisas e reflexões teórico-práticas; a segunda, que trata de aproximações teórico-práticas; além da terceira, focada em tratar experiências, casos e boas práticas do marketing cultural responsável. Esse bilinguismo (literalmente, pois há textos em português e em espanhol, propositadamente, para manter a originalidade do pensamento e levar o convite à troca das leituras e das identidades) vai além dos idiomas: também aborda os dois países - Brasil e Cuba-e duas áreas que por vezes se misturam, se completam e por vezes se digladiam - comunicação e marketing.

No texto "O mercado de captação de recursos em projetos culturais: um estudo de perspectiva", Mitsuru Higuchi Yanaze e Karina Poli Lima da Cunha trazem para a discussão um tema que se amplia em termos de relevância quando falamos do crescimento da demanda por profissionalização no setor da captação de recursos e da maior importância que o setor cultural 
ganha na área corporativa. Nessa linha de relevância Fernando de Almeida Santos e Paula Meyer Soares Passanezi trazem "A importância dos demonstrativos de natureza social e ambiental e a relação com os projetos sociais e culturais", condição sine qua non para o sucesso desse tipo de investimento. Ainda nessa linha, Felipe Chibás Ortiz oferece o trabalho "Gestão de projetos culturais responsáveis, criatividade e marketing digital: reflexões e casos", que se soma à análise presente no artigo "O discurso sustentável em vozes organizacionais", de Vânia Penafieri e Luiz Alberto de Farias.

Encerrando essa primeira parte do livro dois textos trazem a preocupação sobre a estruturação do campo destinado ao processo de formação de projetos culturais. Adriana Clementino discute "A formação dos profissionais da educação do ensino superior para o trabalho com projetos culturais no terceiro setor" e Lucía Grisel Zamora Socías apresenta o trabalho "La comunicación como elemento básico em la gestión institucional de proyectos comunitarios". Os dois textos convergem para o campo que por um lado transcende o olhar corporativo e ao mesmo tempo convergem para ele, seja pela preocupação com a profissionalização altamente requerida, seja pela possibilidade de parcerias para investimentos em imagem e reputação.

A segunda parte, focada em experiências, fundamentalmente, é aberto com o texto "La creatividad comunitaria en los proyectos culturales: experiência de Pogolotti", de Gerardo Barroto Carmona, seguido do texto de Jorge Lino Coloma Ponce "El trabajo cultural y la comunicación en los processos de desarrollo comunitário", que está em linha com o artigo "La comunicación institucional en los proyectos socioculturales comunitarios", de María Antonieta Tarafa Royo. Como se pode ver, há uma grande preocupação com a interação com as comunidades e a relação com o desenvolvimento, como se pode ser constatado em "Medio ambiente y cultura: una propuesta para el desarrollo", de Silvia Miriam Pell del Río, e também em "La cultura popular tradicional y sus portadores en Cuba", escrito por Rafael Lara González.

Encerrando a segunda parte, Kleber Markus e Marília Saveri lançam seu olhar estrangeiro sobre a construção da comunicação em Cuba, com "Comunicação e gênese na ilha", fazendo uma análise sobre um espaço pouco explorado por pesquisadores brasileiros.

A última e terceira parte, destinada a tratar como objeto boas práticas, traz mais uma vez diversas vozes, brasileiras e cubanas, mostrando experiências que podem ser utilizadas como benchmark. Gustavo Martineli Massola, Alessandro de Oliveira dos Santos e Alessandra Blengini Mastrocinque Martins abrem esse espaço do livro com "Turismo de base comunitária: instrumento para o fortalecimento da gestão democrática em quilombos no Brasil", seguido por "El trabajo comunitario desde la experiencia de la Uneac: contribuciones y perspectivas", texto produzido por Juan Rogelio Rivero Ash.

Gisela Arandia Covarrubias coloca em cena importante aspecto das discussões de etnia relacionada à cultura e à equidade racial. Três textos dão conta de experiências com foco comunitário: "Retroalimentación cultural comunitaria: proyecto El Carmelo", de Avelino Víctor Couceiro Rodriguez, "Proyecto culutural comunitario Imagen 3", de Cecilio Avilés Montalvo e María Mercedes Oviede Ramos, e "Desarrollo de formas cooperadas de gestión em la cultura y los proyectos comunitarios: una cuestión de sostenibilidad", de Rigoberto Fabelo Pérez.

Célia Melo, em sua publicação in memoriam, apresenta um belo projeto de acessibilidade à arte no capítulo "Captura da luz". Dois textos encerram a obra enfocando a temática da marca: "A marca como poder simbólico para a transformação social de comunidades no Brasil", de Flávia Cristina Martins Mendes, e "Made in Brazil: marca-país e identidade competitiva aplicadas ao caso brasileiro", de Letícia de Sena Caritá.

As mestiçagens culturais presentes no livro Marketing e comunicação de projetos socioculturais: experiências brasileiras e cubanas nos trazem a ideia de como podemos ampliar nossos olhares por sobre as bordas que dividem os países e encontrar inúmeras similitudes, diversos motivos para nos aproximarmo e com isso melhorar os nossos pensares e os nossos fazeres. A obra merece um amplo e minucioso passeio por entre suas páginas, detidamente desenhadas por seus organizadores. 